give complete protection, so long as the top is closed, but wire and paper silos may not always prove adequate, and a certain amount of dismantling and cutting out may have to be done. Stack or clamp silos afford no protection, and any part that has been splashed or sprayed must be removed and destroyed. Running water is safe, and need cause no anxiety, but water in shallow ponds or storage tanks, if contaminated with blister gas, may remain dangerous for long periods.

Naturally, one hopes that these particular dangers may never arise, but it is comforting to realize that if they should the Ministries of Agriculture and Home Security are alive to the possibilities, and that farmers have been forewarned and advised as to what steps they should take.

\title{
DRUG PLANTS NATIVE TO GREAT BRITAIN
}

\author{
By Dr. W. O. James \\ Botany Department, University of Oxford
}

$\mathrm{A}^{\mathrm{s}}$ PART from herbalist simples, there are some half-dozen or so ${ }^{i}$ plants of Europe and the British Isles which yield drugs of first-class medical importance. The annual consumption of Great Britain runs into hundreds of tons of crude dried material, almost the whole of which normally comes from the Continent, particularly from Belgium, Germany, the U.S.S.R. and the Balkans. Consumption is not limited to the requirements of the people of Great Britain. A re-export trade of refined drugs exists on a considerable scale and, since this largely goes to the western hemisphere, and is economical in its demands on cargo space, there is point in trying to keep it alive at the present time.

First, however, must come home needs. The Ministry of Health has issued several pronouncements stressing "the importance and urgency of the question of supply and, through its Vegetable Drugs Committee, has reviewed the situation and made certain cautious recommendations.

Serious shortage already exists of some of the drugs in question, a situation which had its parallel in the War of 1914-18. The steps taken then were only partially successful, but should af :ord some useful background of experience now, though it is too early yet to say whether the implied lessons have been learnt.

The steps open to us include collection of wild plants and increased cultivation. Each is very narrowly restricted both by botanical and economic causes and will require skilful and determined handling if anything useful is to be achieved. The Ministry of Health has ruled that war-time production must remain on a commercial basis. Strictly speaking, this is impossible. It is true that the produce is being handled through the usual trade channels, but collection depends upon volunteers who can receive nothing commensurate with any normal valuation of their time and labour. This end of the effort is essentially a gift to the country - a commendable if indirect warservice-and should be recognized as such. It is being undertaken by women's institutes, women's voluntary services, boy scouts, girl guides and some schools.

Government assistance has not been lacking. The Ministry of Health has sought to give a lead, and has provided machinery for co-ordination and advice. In hard cash, grants have been given to certain famous and well-established firms to enable them to extend their drying-plant and, on a smaller scale, to the Oxford Medicinal Plants Scheme, which has been called into existence to make selections from the native wild plants, combining trials with a limited scale of present production.

It has been officially recommended by the Ministry of Health and the Medical Research Council that effort be concentrated on belladonna, colchicum, foxglove, male fern, henbane, sphagnum, stramonium, dandelion-root and valerian, with special emphasis on the four italicized. This recommendation does not seem to have received all the attention it deserves. Besides these plants of well-established therapeutic value, the flora of Great Britain contains many more which are normal articles of the drug trade, but the value of which no responsible medical man would put in the same category. Bluntly speaking, nobody is going to die prematurely or suffer great pain for lack of them, as many might suffer or die for lack of belladonna or foxglove. By no efiort of the will can the harvesting of such inessentials be made to appear a significant contribution to the war effort. Nevertheless, judging from the inquiries and literature I have received, there seems to be a real danger of anxious and willing help 
being dissipated upon them. Nor does it appear an adequate argument that there are districts where none of the important drug plants are to be found. In such places, which are, of course, numerous, effort would be better directed to something else; the much-besought women's institute member might better be left at her preservingcentre and her husband on his allotment.

Cultivation is limited to the 'big four', with some valerian. It has its own special difficulties and seed is not easy to come by. Moreover, the market could very easily become over-supplied if cultivation were begun by numerous growers on a large scale. It is clearly undesirable to stimulate a demand for such plants artificially, and for these reasons growing by amateurs and farmers, other than the already established specialists, has not been encouraged. The latter, however, have somewhat expanded their normal acreage.

The appeal for public assistance is concerned with collection. Within my own experience landowners have usually proved helpful and cooperative. A few wish to sell, especially where belladonna is concerned, and there have been very rare refusals of help or permission to collect.

The real crux, however, lies in the question of drying. Fresh herb as collected cannot be transported over any considerable distance both on account of prohibitive cost and of damage by bruising the leaves. Ten or fifteen miles is an extreme range and the latter figure is probably beyond it. It follows that the really worth-while efiort is to get drying-sheds established in the centre of a zone thickly populated by the plant required. This puts foxglove into a class by itself. Valerian root may be collected in some swampy districts; henbane is rare in quantities large enough for commercial gathering. though I have received reports of "fields full" here and there. We are able to collect a small amount of belladonna in Oxfordshire and the adjacent counties, but other resources are slender. Colchicum and male fern are locally abundant and worthy of serious attention in the west. Stramonium is only an occasional escape and inhabitant of waste-tips. The collection of dandelion root is a formidable undertaking and its use for the relief of dyspepsia, valuable though it is, is not to be compared with the irreplaceable role of digitalis as a cardiac stimulant. Foxglove, moreover, exists in abundance over wide areas which are still largely untapped. Initial results obtained by the Oxford Medicinal Plants Scheme, with the co-operation of the Botany Department at Bangor, suggest that the foxglove on the Welsh hills has an unusually high digitalis potency. An exceptional effort towards its gathering would seem to be indicated.
Everyone is agreed that drying-plant must be of a makeshift kind. There is no guarantee of a certain market for these products after the War; in fact they are more than likely to be displaced again by cheap imports from the Continent. Capital sunk in permanent drying-sheds would be sunk indeed. The temporary use of hop-kilns has been suggested; but very considerable additions of shelf-area are needed since drug plants are wetter and need much thinner spreading than hops. Consultation with a firm near Oxford made it clear that the attempt was likely to involve serious financial loss. Forced-air systems with their relatively high running costs appear to be out of the question. Occasionally, institutions are willing to allow the use of large airing-rooms with central heating. Since there is then no further outlay for fuel or shelving, this plan works to admiration. The only method of general application is that of the handyman who can knock up shelves of wood and netting in some available outhouse. When allowance is made for putting in the essential stove, the most modest attempt involves an expenditure of ten or fifteen pounds. Ten pounds is the market value of about $2 \mathrm{cwt}$. of dried foxglove leaf, or getting on for a ton of leaf as gathered-far more than such a shed could handle in a single season, and this is making no allowance for coke and other costs of operation. There is also implied a great deal of active gathering by a considerable number of women or supervised children in the field and a great deal of uncomfortably hot and tiring work spreading and turning the leaf in the driers.

Each drying-centre, small though it may be, needs the constant supervision of a man or woman of untiring and persuasive nature to keep it actively in operation. A modicum of expert knowledge is also needed, and there is much greater scope and need for the help of botanists on the spot than has yet been realized. Botanists are often exercised at the present time as to how they can turn their special training to the public good. Those of a practical turn could find something valuable and patriotically useful to do in building up and running such drying-centres. It need not be at all a routine job. Very little seems to be known about the best methods of drying, a purely empirical judgment of colour being a common basis of values. There is need for the collection of numerous data both for direct technical and more academic purposes. This amounts to a good deal more than spare-time work and can probably only be achieved as a recognized activity for a botany department. In my view, the help of many more such institutions and their personnel is essential if this war-time emergency work is to be carried out with full success. 